\title{
A Novel Compact Wide Band CPW fed Antenna for WLAN and RFID Applications
}

\author{
N.V. Rajasekhar ${ }^{1}$, K.Anusudha ${ }^{2}$ \\ ${ }^{I}$ Department of Electronics Engineering, Pondicherry University, India \\ ${ }^{2}$ Asst.Professor, Department of Electronics Engineering, Pondicherry University, India
}

\begin{abstract}
A wide band CPW fed antenna for wireless communication applications such as WLAN $(5.2 \mathrm{GHz})$ and RFID $(5.8 \mathrm{GHz})$, is presented in this paper. The antenna consist of finite substrate dimensions $(20 \times 15$ $\mathrm{mm}^{2}$ ).This antenna is realized on FR4 epoxy substrate with permittivity 4.4 and loss tangent of 0.002.It has desired antenna characteristics such as return loss better than 10dB, VSWR, gain and radiation pattern at the specified resonant frequencies. The B.W of antenna $(1130 \mathrm{MHz})$ is greatly improved by optimizing the width and length of the slots. The antenna is simulated using Mentor Graphics IE3D 15.10 electromagnetic solver and fabricated. There is good matching between measured and simulated results.
\end{abstract}

Keywords: Antenna parameters, CPW fed, RFID, WLAN, Wide band.

\section{INTRODUCTION}

Modern wireless communications systems are placing greater demands on antenna designs. Many systems now operate in two or more frequency bands, requiring dual or triple band antennas. These include satellite navigation systems, cellular systems, WLAN, WiMAX, RFID and combinations of all these. Recently, wireless communications have been developed widely and rapidly, which leads to a great demand in designing low profile, and multiband antennas for mobile terminals. Many antennas, such as the folded dipole antenna, Inverted F antenna, CPW-fed Folded-slot Antenna with wide band characteristics have been reported [1-6] which have large dimension when compared to proposed antenna.

Along with the size reduction demand, dual/triple-band design is definitely necessary for many applications, such as WLAN and RFID, so that dual/multiband antenna designs with compact patch size are desired. More-over, frequency tuning ability is very useful to implement the design to a variety of applications.

In recent years, Radio Frequency Identification (RFID) technology has been extensively utilized in modern supply chain management to identify and track goods. Usually, a basic RFID system is made up of two components: one is the transponder, which is located on the object to be identified and the other is the reader, which, depending upon the design and the technology used, may be a read or write/read device [7]. The tag's antenna receives signals from an RFID reader and then sends back the signals, usually including some additional data, including a unique serial number or customized information. The frequency bands assigned to RFID application are less than $135 \mathrm{KHz}, 13.56 \mathrm{MHz}$, UHF band and microwave band, including $2.45 \mathrm{GHz}$ and 5.8 GHz. As the operating frequency for RFID system raises into microwave region, the tag antenna design becomes more acute and essential [8]. The tag antennas must be small enough to be attached to the required object and have omnidirectional or hemispherical coverage. Besides, the cheap cost and proper impedance are also required.

In this paper, a new wideband, planar impedance-matching scheme is achieved by using a simple rectangular strip with CPW fed dumbbell like slots without any structural complexities. The antenna has a 2:1 VSWR bandwidth of $1130 \mathrm{MHz}$ from (5.17- 6.30) GHz, covering for wireless communication applications such as WLAN (5.2 GHz) [9] and RFID (5.8 GHz).The rest of paper is organized as follows. Antenna Design and Structure are presented in Section II. Simulation and Measured results are discussed in section III. Conclusion is given in section IV. 


\section{ANTENNA DESIGN AND STRUCTURE}

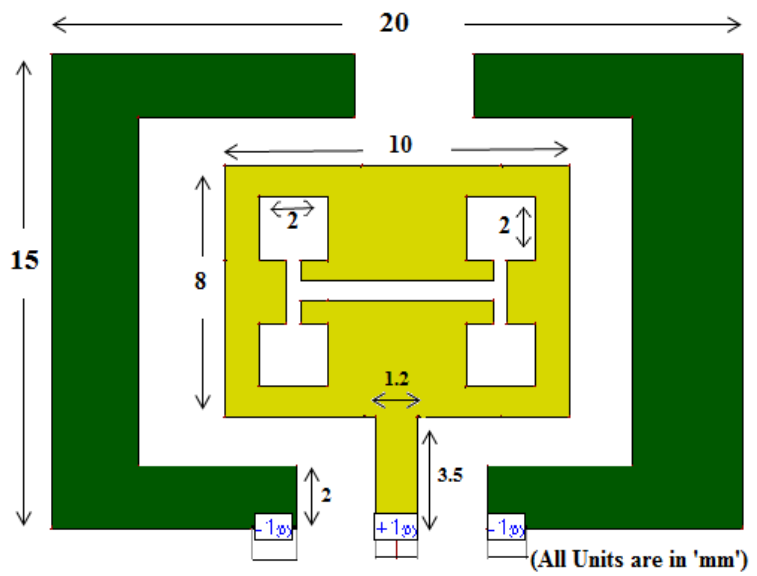

Fig.1: Geometry of Proposed Antenna.

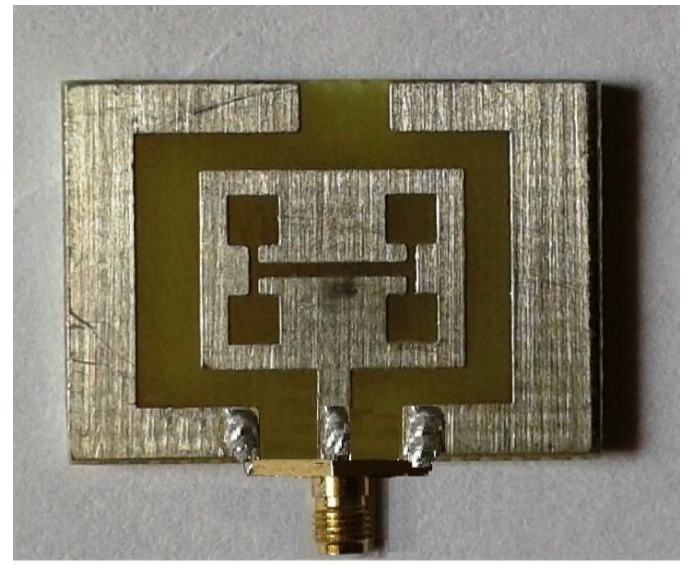

Fig.2: Fabricated Proposed Antenna.

The following design procedure is used to design this antenna with good radiation characteristics.

Specify: Dielectric constant, $\mathrm{f}_{\mathrm{r}}$ (in $\mathrm{GHz}$ ) and $\mathrm{h}$ (in $\mathrm{mm}$ ).

Here,

$$
\begin{aligned}
& f_{r} \text { is the resonance frequency. } \\
& \varepsilon_{r} \text { is the dielectric constant. } \\
& h \text { is the thickness of substrate. }
\end{aligned}
$$

Determine: width and length of ground plane, patch and the strip width, gap width, length and width of slot.

1. The parameters of the ground plane are calculated as below [10]

$$
\begin{array}{r}
L=\frac{0.088 c}{f_{r} \sqrt{\varepsilon_{r e f}}} \\
W=\frac{0.066 c}{f_{r} \sqrt{\varepsilon_{r e f}}}
\end{array}
$$

Where,

$$
\varepsilon_{r e f}=\frac{\varepsilon_{r}+1}{2}
$$

The coefficients 0.088 and 0.066 are derived empirically after studying the effect of ground plane on the impedance matching for the antenna.

2. For an efficient radiator, a practical length of patch considered as $0.28 \lambda_{g}$ where $\lambda_{g}$ is guided wavelength which is equal to $\lambda_{0} / \sqrt{\varepsilon_{\text {reff }}}$ and the width of the patch that leads to good radiation efficiency is $W_{P}=1.5 L_{P}$.

3. The length of slots considered as $\leq L_{p} / 2$, width of slot is calculated as $1 / 0.11 L_{P}$.

4. To excite the antenna, a $50 \Omega \mathrm{CPW}$ transmission line, having a strip of width $\mathrm{S}$ and a gap of distance W between the signal strip and the ground plane, is used. The expression for the strip width $s$ and gap width $w$ are given below [11]

$$
\begin{aligned}
\frac{s}{h} & \leq \frac{80}{3\left(1+\ln \varepsilon_{r}\right)} \\
\frac{w}{h} & \leq \frac{10}{3\left(1+\ln \varepsilon_{r}\right)}
\end{aligned}
$$


The values of the design parameters calculated using the presented method and optimized using IE3D software. The detailed dimensions of a CPW fed antenna with slots patch shown in Figure 1.

The geometry of proposed antenna is as shown in the figure 1. The total dimension of antenna is $20 \times 15 \times 1.6 \mathrm{~mm}^{3}$ which are obtained by mathematical design formulae. The rectangular patch dimension as shown in the fig 1 is $10 \times 8 \mathrm{~mm}^{2}$. Figure 2 shows the fabricated antenna. The proposed structure exciting strip is embedded with two dumbbells connected by another rectangular slot. Here we had taken all the slots of identical dimensions. The slot with dimension $2 \times 2 \mathrm{~mm}^{2}$ which yields the optimum result when compare to other slot cross-section areas. These different dumbbell shape slot mocrostrip antennas are designed and simulated using Electromagnetic solver. The slots on the patch are useful for avoiding the surface wave effect and improving the bandwidth. A CPW feed is employed for providing excitation which is far superior compared with other feeding mechanisms.

The proposed antenna is realized on $1.6 \mathrm{~mm}$-thick FR4 substrate with permittivity 4.4 and loss tangent of 0.002 . The antenna fed by $50 \Omega \mathrm{CPW}$ feed line with the width of $1.20 \mathrm{~mm}$ and length of $3.5 \mathrm{~mm}$ as shown in the fig 1.On the radiator two dumbbells like slots are placed with supported dumbbell in the middle of them as shown in the fig1.The dimension of the square slots on the patch is $2 \times 2 \mathrm{~mm}^{2}$. The B.W of antenna $(1130 \mathrm{MHz})$, return loss, VSWR and gain of antenna, such desired antenna parameters are greatly improved by optimizing the width and length of the slots. The optimum gap between slots and patch from all sides is $0.6 \mathrm{~mm}$ and the distance between two dumbbells is $5.8 \mathrm{~mm}$. All the dimensions of the proposed antenna are optimized with IE3D electromagnetic solver and the optimum dimensions of antenna are shown in figure 1.

\section{RESULTS AND DisCUSSION}

The simulation of the proposed antenna is done using Mentor Graphics IE3D 15.10 [10]. The fabricated antenna is tested by using Vector Network Analyzer (VNA).Figure 3 shows the simulated return loss characteristics of the proposed antenna. The optimum return loss of antenna is $-10 \mathrm{~dB}$ down. From figure 3 , it is observed that return loss $-10 \mathrm{~dB}$ down from $5.17 \mathrm{GHz}$ to $6.3 \mathrm{GHz}$. The antenna has maximum return loss of -21 $\mathrm{dB}$ and $-33 \mathrm{~dB}$ at the resonant frequencies $5.2 \mathrm{GHz}$ and $5.8 \mathrm{GHz}$ respectively. This return loss had given good match for WLAN and RFID applications. The antenna bandwidth is greatly improved by adjusting dimensions of slots on the radiator, which had obtained wide bandwidth of $1130 \mathrm{MHz}$ as shown in figure 3 . Figure 4 shows the simulated VSWR of the proposed antenna. The desirable VSWR of any antenna is $2: 1$. The antenna has VSWR 2:1 down from $5.17 \mathrm{GHz}$ to $6.3 \mathrm{GHz}$. The antenna has maximum VSWR of 1.19 and 1.04 at the resonant frequencies $5.2 \mathrm{GHz}$ and $6.3 \mathrm{GHz}$ respectively. Figure 5 shows comparison between simulated and measured return loss parameter .From that it is observed good matching between simulated and measured results..

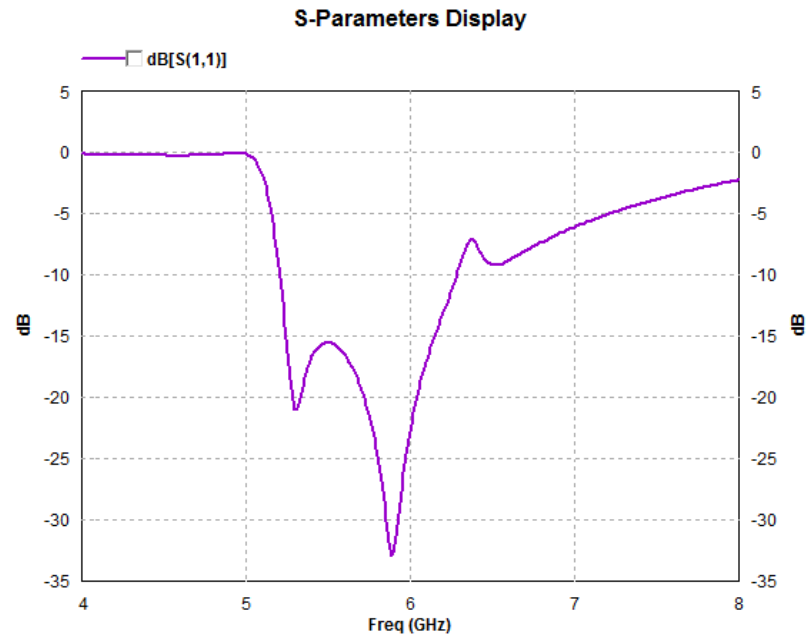

Fig.3: Simulated Return loss of Proposed Antenna

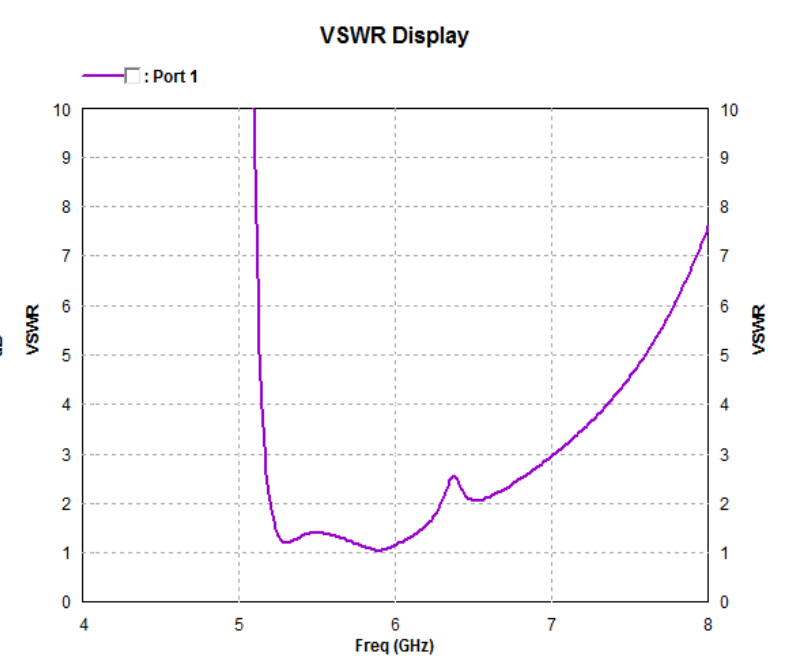

Fig.4: Simulated VSWR of Proposed Antenna 


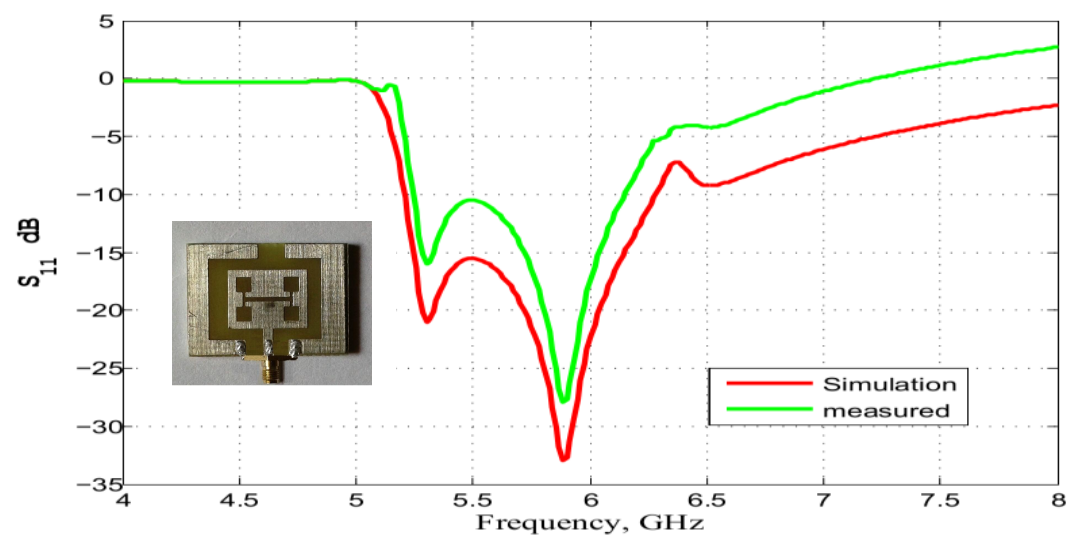

Fig 5: Measured and Simulated results of the proposed antenna.

Figure 6 shows the simulated gain of the proposed antenna. The antenna has gain of $2 \mathrm{dBi}$ above from 5.17 $\mathrm{GHz}$ to $6.3 \mathrm{GHz}$, which is very suitable for WLAN and RFID applications. It has peak gain $3.9 \mathrm{dBi}$ at $5.2 \mathrm{GHz}$, $3.5 \mathrm{dBi}$ at $5.8 \mathrm{GHz}$. Figure 7 shows the efficiency of simulated antenna. Usually the efficiency of antenna should be greater than $70 \%$. The antenna has efficiency greater than $70 \%$ from $5.2 \mathrm{GHz}$ to $6.0 \mathrm{GHz}$. The antenna has $88 \%$ efficiency at $5.2 \mathrm{GHz}$ and $75 \%$ at $5.8 \mathrm{GHz}$ as shown in the figure 7 .

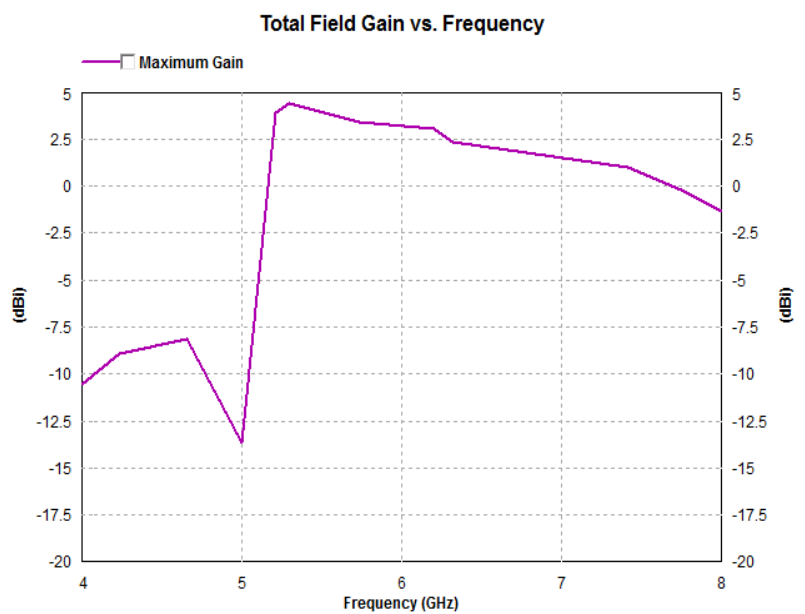

Fig.6:Gain Characterstics of Proposed Antenna

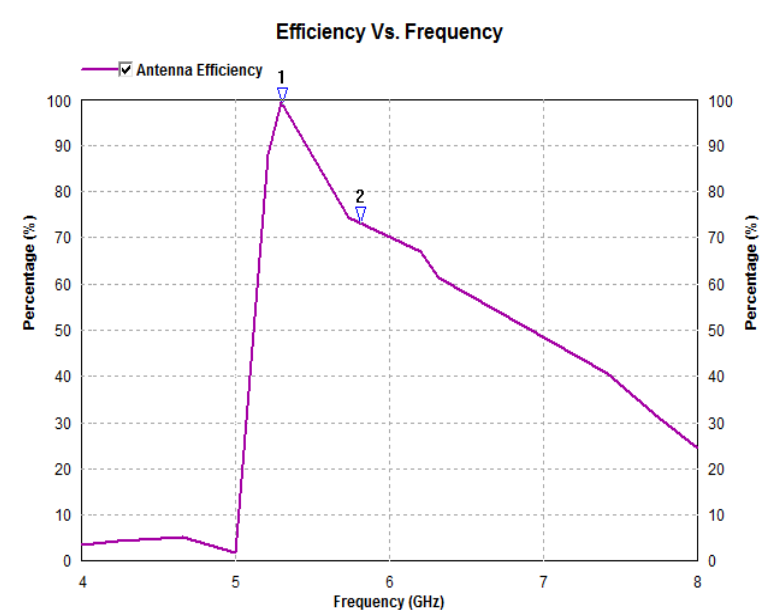

Fig.7: Simulated Efficiency Characterstics of Proposed Antenna

Figure 8 shows the simulated current distribution of proposed CPW fed antenna for two resonances. From figure 8 (a), it's clear that at $5.2 \mathrm{GHz}$ the current is perturbed across the slots, more comparing with remaining part so it causes the resonance at the particular frequency. From figure $8(\mathrm{~b})$, at $5.8 \mathrm{GHz}$ the current is perturbed across feed line and ground plane, more comparing with remaining part, which causes the resonance at particular frequency.

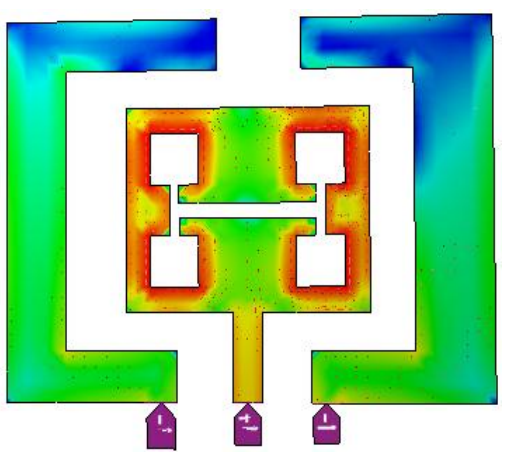

(a)

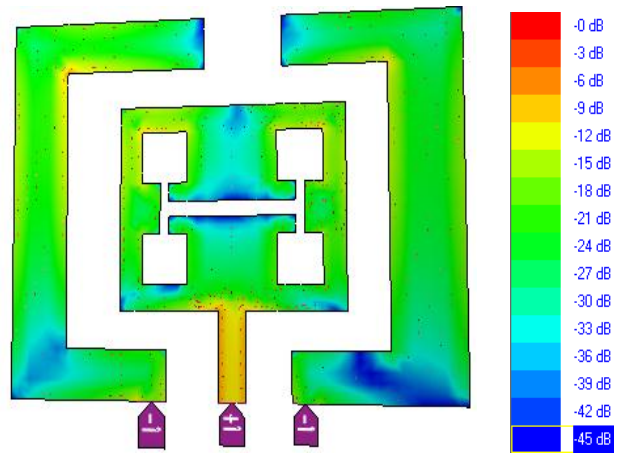

(b)

Fig.8 : Current Distribution of Proposed Antenna (a) at $5.2 \mathrm{GHz}$ (b) at $5.8 \mathrm{GHz}$ 
The figure 9 and figure 10 shows the simulated radiation patterns of proposed antenna with Elevation and azimuthl at two different frequencies of resonance with respect to gain by using Electromagnetic solver respectively. The simulated radiation patterns of antenna in the E-plane (XZ -plane) at $5.2 \mathrm{GHz}$ and $\mathrm{H}$-plane (YZ-plane) at $5.8 \mathrm{GHz}$ are shown in figure 9 and figure 10, respectively. The patterns and other curves are obtained at the time of simulation.Good radiation patterns are observed by taking 20 cells per wavelength. The desired parameters of proposed antenna are tabulated in Table 1.

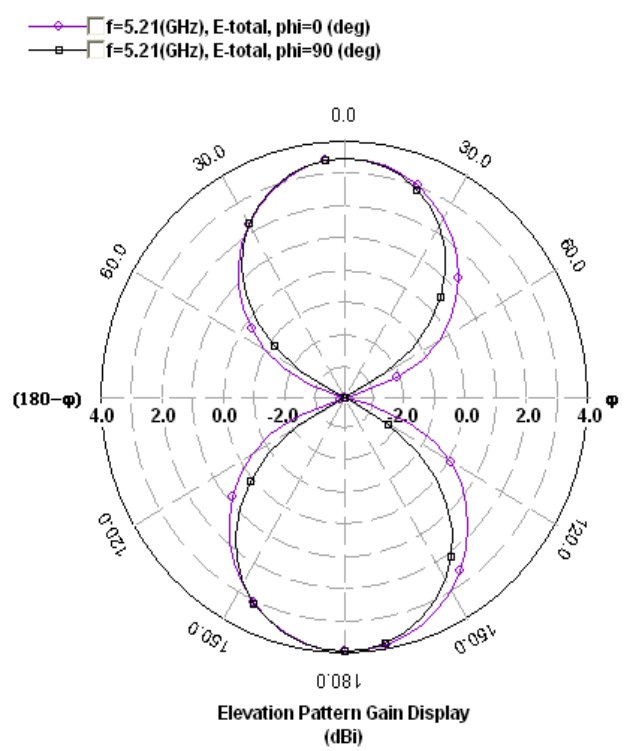

(a)

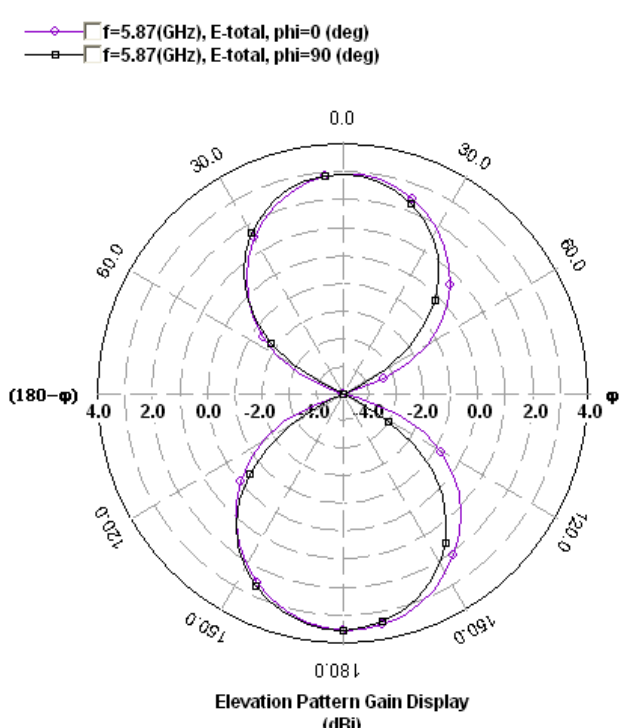

(b)

Fig.9: 2D Radiation Elevation Pattern of Antenna (a) at $5.2 \mathrm{GHz}$ (b) at $5.8 \mathrm{GHz}$

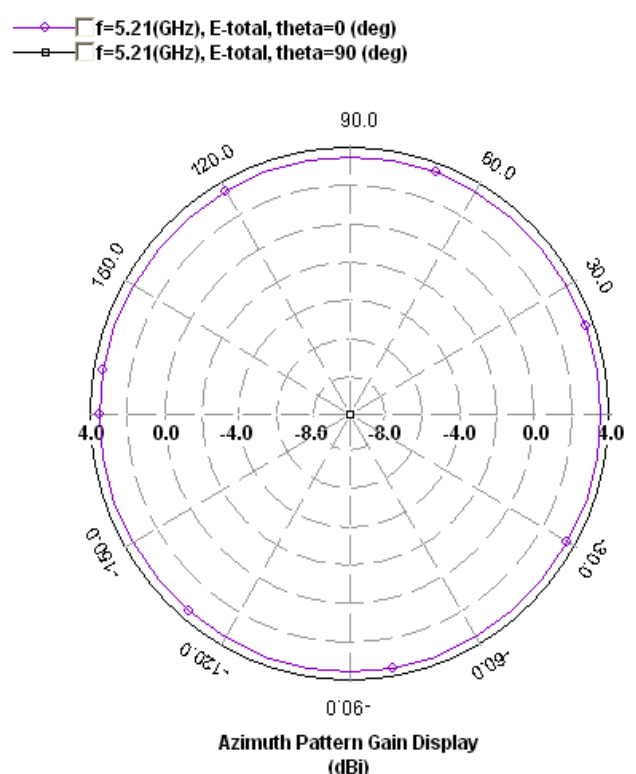

(a)

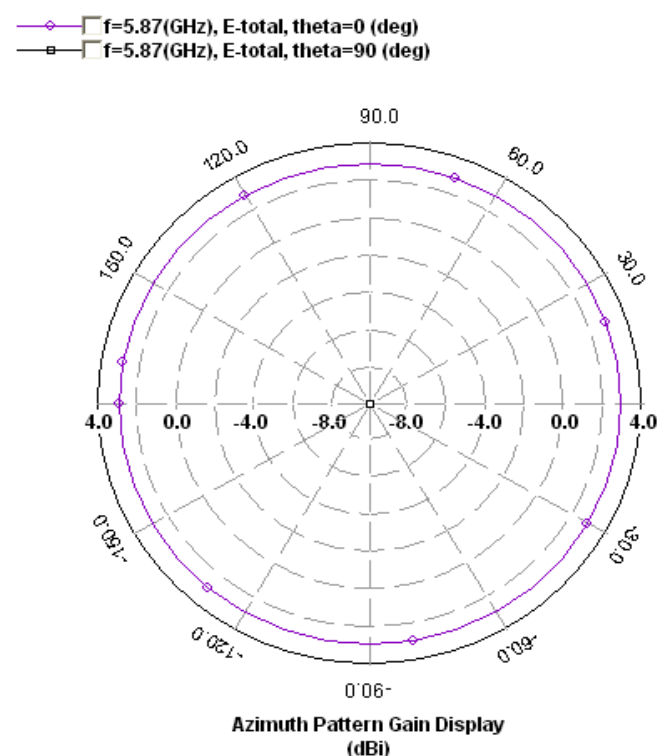

(b)

Fig.10: 2D Radiation Azimuthal Pattern of Antenna (a) at $5.2 \mathrm{GHz}$ (b) at $5.8 \mathrm{GHz}$ 
TABLE I: DESIRED PARAMETERS OF PROPOSED ANTENNA.

\begin{tabular}{|c|c|}
\hline \multirow{2}{*}{ Parameter } & Proposed Antenna \\
\hline \multirow{3}{*}{ Return loss } & $-10 \mathrm{~dB}$ down at $(5.17-6.3) \mathrm{GHz}$ \\
& $-21 \mathrm{~dB} @ 5.2 \mathrm{GHz}$ \\
& $-33 \mathrm{~dB} @ 5.8 \mathrm{GHz}$ \\
\hline \multirow{2}{*}{ VSWR } & 2 down at $(5.17-6.3) \mathrm{GHz}$ \\
& $1.19 @ 5.2 \mathrm{GHz}$ \\
& $1.04 @ 5.8 \mathrm{GHz}$ \\
\hline \multirow{2}{*}{ Bandwidth } & $1130 \mathrm{MHz}$ \\
\hline \multirow{2}{*}{ Gain } & $3.9 \mathrm{dBi} @ 5.2 \mathrm{GHz}$, \\
& $3.5 \mathrm{dBi} @ 5.8 \mathrm{GHz}$ \\
\hline \multirow{2}{*}{ Efficiency } & $88 \% @ 5.2 \mathrm{GHz}$ \\
& $75 \% @ 5.8 \mathrm{GHz}$. \\
\hline
\end{tabular}

\section{CONCLUSION}

A Novel wideband CPW fed antenna for WLAN and RFID applications, has been designed and simulated using Mentor Graphics IE3D 15.10 electromagnetic solver. The fabricated antenna has been tested using VNA and good matching is obtained between measured and simulation results. The results presented have shown that, the broad impedance bandwidth and good radiation characteristics are obtained in both Centre frequencies of operation. The proposed antenna has compact dimensions compared with existing geometries presented in the literature. The wide band of operation of $1130 \mathrm{MHz}$ is achieved, which is more suitable for WLAN and RFID Applications.

\section{REFERENCES}

[1] Chen, S. Y. and P. Hsu, "CPW-fed folded-slot antenna for $5.8 \mathrm{GHz}$ RFID tags," Electron Letter, Vol. 40, No. 24, 1516-1517, 2004.

[2] Li, K., C. H. Cheng, T. Mastui, and M. Izusu, "Coplanar patch antennas," Proceedings of IEEE MTT-S Int. Microwave Sym., 402405, 2001.

[3] Qing, X. and N. Yang, "A folded dipole antenna for RFID," Proceedings of Antennas and Propagation Society International Symposium, 97-100, 2004.

[4] Ukkonen, L. and L. Sydanheimo, "A novel tag design using inverted-F antenna for radio frequency identification of metallic objects," Proceedings of Advances in Wired and Wireless Communication, 2004 IEEE /Sarnoff Symposium, 91-94, 2004.

[5] T.Shanmuganantham, K. Balamanikandan, and S.Raghavan, "CPW-Fed Slot Antenna for Wideband Applications," International Journal of Antennas and Propagation, Vol. 2008, pp.1 - 4, Hindawi Publication,U.S.A., 2008.

[6] Keskilammi M., and Kivikoski, M.: "Using text as a meander line for RFID transponder antennas", IEEE Antennas Wirel. Propag. Lett, 3, (1), pp. 372-374, 2004.

[7] Finkenzeller, K., RFID Handbook [M], 2nd edition, Wiley, London, 2004.

[8] Foster, P. and R. Bueberry, “Antenna problems in RFID systems," IEE Coll. on RFID Technology, 3/1-3/5, 1999.

[9] J.-H. Yeh, J.-C. Chen and C.-C. Lee, "WLAN standards", IEEE Poten-tials, vol. 22, no. 4, pp. 16-22, Oct.-Nov. 2003.

[10] Qing-Xin Chu and Liang-Hua Ye "Design of Compact Dual-Wideband Antenna With Assembled Monopoles," IEEE Trans.Antennas Propag, vol. 58, No. 12, December 2010

[11] Rainee N. Simons, "Coplanar Waveguide Circuits, Components, and Systems”, John Wiley \& sons, inc., New York, March 2001 Edition. 